\title{
Polityczność, polityka i Pan Nergal w kontekście tabloidyzacji polskiej sceny politycznej
}

W $\begin{aligned} & \text { publikacji Polityczność. Przewodnik Krytyki Politycznej Chantal } \\ & \text { Mouffe napisała, że w przeciwieństwie do tego, do czego chca nas }\end{aligned}$ przekonać postpolityczni politycy, obecnie nie doświadczamy zaniku polityczności w jej antagonistycznym wymiarze, ale czegoś zupełnie odmiennego. Polityczność jest dziś rozgrywana w „rejestrze moralności” definiowanym nie w kategoriach politycznych, lecz w języku moralnym. Miejsce konfliktu „prawicy z lewicą” zajmuje „walka dobra ze złem"" . Podczas ostatniej kampanii wyborczej (w 2011 roku) znalazł się na szczęście temat, który pogodził wszystkie środowiska i opcje polityczne - posła Niesiołowskiego z posłem Hofmanem, prawicę z prawicą i lewicą. W kampanijnych strategiach wyborczych, prezes Jarosław Kaczyński, szukając nowych punktów, które mogłyby spolaryzować stanowiska społeczne i wprowadzić tak lubianą przez środowisko PiS dychotomię (charakterystyczną dla mouffowskiej polityczności): dobre-złe, my-wy, zwrócił się w stronę alternatywnej, metalowej sceny muzycznej. Stwierdzając, że jeden z artystów, ostatnimi czasy bywający w mediach, a co za tym idzie rozpoznawalny nie tylko dla wąskiej grupy fanów death metalu, niszczy polską demokrację. Adam Darski pseudonim Nergal, lider zespołu Behemoth, zupełnym przypadkiem (bo nie został wynajęty przez żaden z PR-owych politycznych sztabów wyborczych) odsłonił nową prawdę o polskim społeczeństwie i o wpływie mediów na kształtowanie opinii publicznej, a co za tym idzie, polityki.

Tematem dominującym okazał się bowiem spór o rolę i miejsce artysty Nergala w społeczeństwie polskim. Dyskusja nad tym społeczno-polityczno-moralnym problemem obrosła taką legendą, że nagle okazała się sporem o podstawy polskiej demokracji.

1 Ch. Mouffe, Polityczność. Przewodnik krytyki politycznej, Warszawa 2008, s. 20 . 
Celem artykułu jest analiza tego zjawiska. Na pewno jest to jeden z wymiarów tabloidyzacji polskiej sceny politycznej, ale w odwrotnym kontekście dyskursu naukowego, niż ten, który jest znany i analizowany współcześnie. Nie mamy tu bowiem do czynienia ze zjawiskiem politycznej rozrywki (politainment), polityków-celebrytów i politycznego memplexu w potocznym rozumieniu, ale obserwujemy artystę-celebrytę, który został wciągnięty do politycznego dyskursu przez polityków.

Wydaje się, że może być to zjawisko klasyczne właśnie dla ontycznego świata postpolityki (czyli tego, który definiuje praktyki konwencjonalnej polityki) wskazywanego przez Chantal Mouffe ${ }^{2}$. W jej ujęciu „polityczność” i ,polityka”, to dwa różne obszary działania. Przez ,polityczność" rozumie ona wymiar antagonistyczny leżący u podstaw każdego ludzkiego społeczeństwa, przez politykę zestaw praktyk i instytucji, które w obliczu wprowadzanego przez polityczność konfliktu tworzą porządek umożliwiający ludzkie współistnienie ${ }^{3}$. Należy pamiętać, że owa „polityczność” umieszczana jest w ramach, które definiują współczesny dyskurs medialno-polityczny, czyli w erze postpolitycznej. Jej charakterystykę dobrze ukazał Eryk Mistewicz, twierdząc, że w świecie postpolityki emocje zajęły miejsce programów wyborczych, a wizerunek zdystansował idee ${ }^{4}$. Tworzy nową arenę dla demokracji, nową architekturę, scala politykę z technikami komunikacyjnymi. Nie dąży do tłumaczenia nikomu, niczego. Nie ma autorytetów i elit w dotychczasowym rozumieniu tego słowa. Komunikacja polityczna skupia się na dotarciu do jak najszerszej grupy ludzi poprzez operowanie obrazami, zapadającymi w pamięć i rozbudzającymi namiętności i emocje ${ }^{5}$.

Jeżeli zatem za podstawę funkcjonowania ,ppolityczności” w świecie postpolityki przyjmiemy konflikt i potrzebę utrzymywania dychotomii, ale nie na poziomie rywalizacji ideologicznej prawica-lewica, ale na poziomie moralnym, ontologicznym: dobro-zło, lub na poziomie differentia specifica, wskazywanej prze Carla Schmitta ${ }^{6}$ : przyjaciel-wróg;

2 Patrz: ibidem, s. 23.

3 Ibidem, s. 24.

${ }^{4}$ E. Mistewicz, Idee nieważne, ważna władza, „Uważam Rze”, nr 4, s. 68.

5 B. Machnik, Postpolityka. Idee nieważne - ważna władza, „Nowa Politologia", 20.05.2011, artykuł dostępny na: http://www.nowapolitologia.pl/politologia/marketing-polityczny/postpolityka-idee-niewazne-wazna-wladza (maj 2012).

${ }^{6}$ Ch. Mouffe, op. cit., s. 26. 
my-oni; to zamieszanie wywołane wokół osoby pana Darskiego nabiera nowego znaczenia.

\section{Demokracja społeczeństwa medialnego}

Kolejną cechą polityczności, oprócz antagonizacji, jest hegemoniczność, konstytuująca więzi i charakter danego społeczeństwa ${ }^{7}$. O współczesnych społeczeństwach coraz częściej mówi się jako o społeczeństwach medialnych, czy też szerzej globalnych społeczeństwach medialnych, czyli takich, które są już przesycone mediami, w których nastąpiła mediatyzacja dyskursu politycznego. Oznacza to, że coraz więcej elementów ze świata realnego przeniesione zostało i rozgrywa się w mediach ${ }^{8}$. Mediatyzacja (medializacja) wyznacza nowe relacje i zależności między polityką a mediami. Wpływa bezpośrednio na procesy polityczne, decyzje obywateli i elit oraz określa sposoby kształtowania woli i artykulacji interesów. Nowoczesne społeczeństwo przybiera zatem charakter społeczeństwa medialnego. Systemy medialne zmieniają struktury społeczne, bez względu na to, które z doktrynalnych stanowisk przyjmiemy, czy ujęcie pluralistyczne, strukturalistyczne, konstruktywistyczne, czy też koncepcję kolonizacji, trzeba zgodzić się, że media ingerują głęboko w różne sfery życia9 .

Zjawisko, o którym mowa, jest obecne równolegle w kilku sferach demokratycznego społeczeństwa. Odnosi się do zmian społecznych we współczesnych wysoko rozwiniętych społeczeństwach i do roli mediów oraz komunikacji w tych przemianach. Procesy mediatyzacji wywieraja wpływ na prawie wszystkie obszary życia społecznego i kulturowego ${ }^{10}$. Polityka, jak się ją często zaczęło określać, stała się widowiskiem. Media właśnie takiej konwencji chcą, czy też taką muszą się posługiwać.

${ }^{7}$ Ch. Mouffe, op. cit., s. 32-33.

8 J. Zdański, Demokracja w dobie społeczeństwa medialnego, w: Mediatyzacja kampanii politycznych, red. M. Kolczyński, M. Mazur, S. Michalczyk, Katowice 2009, s. 48.

${ }^{9}$ Mediatyzacja kampanii politycznych, red. M. Kolczyński, M. Mazur, S. Michalczyk, Katowice 2009, s. 8; T. Olczyk, Politrozrywka i popperswazja. Reklama telewizyjna w polskich kampaniach wyborczych XXI wieku, Warszawa 2009, s. 87.

10 D. Piontek, Komunikowanie polityczne i kultura popularna. Tabloidyzacja informacji o polityce, Poznań 2011, s. 43. 
Scena życia politycznego posiada jedną, bardzo istotną właściwość, a mianowicie ogromną widownię, dla której i wobec której odbywa się przedstawienie $^{11}$. Jak konstatuje Peter Dahlgren, polityka nie istnieje już jako rzeczywistość mająca miejsce poza mediami, a jedynie jako relacjonowana przez dziennikarzy ${ }^{12}$.

Gdy do tego dodamy kolejny wymiar konfliktu, ukazywany przez „konfliktową polityczność”, jasne stanie się, że podstawowym zadaniem i polityki, i mediów jest absorbowanie uwagi opinii publicznej pewnym widowiskiem, które wskazuje na jakiś konflikt światopoglądowy, niekoniecznie wszak związany z rzeczywistym problemem/kryzysem/poglądem $^{13}$. Postpolitycznej polityce i polityczności bardzo dobrze koegzystuje się z mediatyzacją, która ułatwia przeniesienie każdej dyskusji politycznej z poziomu hard news na soft news, a przykład Nergala pokazuje, że i odwrotna praktyka nie tylko jest możliwa, ale i przynieść może pożądane przez klasę polityczną i media efekty.

Idea społeczeństwa medialnego poza wymiarem technologicznym (nowe media, nowy wymiar i obszar komunikacji politycznej) ma również swój wymiar polityczno-kulturowy, który przejawia się w trzech zasadniczych aspektach:

Po pierwsze, w zmianie znaczenia elity politycznej, która nie jest już elitą sesnu stricto i chociaż nadal jest czynnikiem podtrzymującym istnienie demokracji ${ }^{14}$, jest również źródłem sensacji, afer, skandali.

Po drugie, w tworzeniu politycznej rozrywki (politainment), która obok rozrywki informacyjnej (infotainment) definiuje przestrzeń społeczno-polityczną. Widoczne jest to po pierwsze w działaniach podejmowanych przez polityków w zakresie współpracy z mediami. Jak wskazuje Lisbet van Zoonen: „politycy coraz częściej wykorzystują media rozrywkowe po to, aby omijać dziennikarzy politycznych i na fali rozrywki,

11 B. Blachnicki, Obywatele na scenie życia politycznego - ewolucja czy rewolucja, w: Współczesna przestrzeń polityczna. Ewolucja czy rewolucja, red. M. du Vall, M. Majorek, A. Walecka-Rynduch, Kraków 2011, s. 38.

12 P. Dahlgren, The transformation of democracy?, cyt. za.: T. Olczyk, Politrozrywka i popperswazja. Reklama telewizyjna w polskich kampaniach wyborczych XXI wieku, Warszawa 2009, s. 95.

13 S. Sierakowski, Prawica: cynizm i zmęczenie, „Gazeta Wyborcza” z 18-19.08.2007, za: L. Rubisz, Polityka $i$ widowisko, w: Mediatyzacja kampanii politycznych, red. M. Kolczyński, M. Maur, S. Michalczyk, Katowice 2009, s. 113.

14 E. Etzioni-Halevy, Władza $w$ demokracji: teoria elit demokratycznych, w: Przyszłość demokracji. Wybór tekstów, red. P. Śpiewak, Warszawa 2005, s. 110. 
skandalu, zaszokowania dotrzeć do odbiorców"15. Po drugie w strategiach wyborczych partii politycznych polegających na udziale w kampanii politycznej tzw. wolnych jeźdźców, czyli osób znanych, cenionych, cieszących się autorytetem i wiarygodnością ${ }^{16}$, lub po prostu ludzi znanych z tego, że są znani - tzw. celebrytów ${ }^{17}$, ale również muzyków, zespołów muzycznych, które występują na wiecach z tzw. ,piosenką wyborczą"18, zaskarbiając cenne głosy elektoratu.

Trzecim aspektem omawianego problemu jest tabloidyzacja ${ }^{19}$ dyskursu politycznego i sceny politycznej. Sam termin jest trudny do zdefiniowania, bowiem - jak podkreśla Dorota Piontek - zawiera przynajmniej dwa komponenty znaczeniowe. Jest procesem i zjawiskiem - następstwem procesu. Oznacza nabywanie cech tabloidu przez prasę codzien-

15 L. van Zoonen, Popular culture as political Communications, za: D. Piontek, Politycy i media. Sposoby wplywania przez polityków na zawartość mediów, w: Polska scena polityczna. Środowiska - komunikacja polityczna - strategie, red. K. Sobolewska-Myślik, A. Hess, K. Kowalczyk, Kraków 2010, s. 147.

16 B. Dobek-Ostrowska, Komunikowanie polityczne i publiczne, Warszawa 2007, s. 243 .

17 Patrz: M. du Vall, A. Walecka-Rynduch, Politicaltainment jako przejaw tabloidyzacji polityki, w: Państwo i Społeczeństwo, Oficyna Wydawnicza AFM, Kraków 2012 - tekst w druku.

18 Takich zdarzeń polska polityka również odnotowała już sporo. Wystarczy wymienić zespoły disco polo zaangażowane w kampanię prezydencką w 1995 roku: Bayer Full w kampanię Waldemara Pawlaka - z piosenką „Prezydent” zachęcał słynną frazą „nie z prawicy, lecz z pracy dobrobyt jest i byt”, Top One z hitem „Ole, Ole, Olek”. W 2007 roku senator i wokalista Tadeusz Skotnicki śpiewał „Kilka prostych słów” dla PiS, a Ich Troje zaprezentowało się z hitem „Dokąd idziesz Polsko” - promującym Samoobronę. W kampanii prezydenckiej w 2010 roku seksowne aniołki (zespół 2Sistars) promowały Grzegorza Napieralskiego piosenką „Są nas miliony". W zeszłorocznych wyborach hitem okazała się piosenka wyborcza zespołu Enej dla PSL, „Człowiek jest najważniejszy”. W wideoklipie oprócz młodych, uśmiechniętych ludzi, wystąpili też członkowie partii, m.in. wicepremier Waldemar Pawlak, wicemarszałek Sejmu Ewa Kierkowska, minister pracy Jolanta Fedak czy szef klubu Stanisław Żelichowski, patrz: http://teksty.org/bayer-full,prezydent,tekst-piosenki (maj 2012) oraz http://polska.newsweek.pl/-czlowiek-jest-najwazniejszy_-psl-ma-piosenke-wyborcza,81252,1,1.html (maj 2012).

19 Pojęcie tabloidyzacji dziennikarstwa pojawiło się w literaturze medioznawczej w latach 80. XX wieku. Wiązane było ze zmianami, które zachodziły w mediach tzw. opiniotwórczych i informacyjnych, będącymi wynikiem wytworu technologicznego i postępującej komercjalizacji mediów. Patrz: D. Piontek, Komunikowanie polityczne i kultura popularna. Tabloidyzacja informacji o polityce, Poznań 2011, s. 187. 
ną i magazynową. Widać to zwłaszcza w serwisach internetowych, np. gazeta.pl. Stąd obserwujemy współcześnie takie procesy i zjawiska, jak tabloidalna kultura czy tabloidyzacja polityki ${ }^{20}$. W literaturze przedmiotu wskazuje się na funkcjonowanie kilku wyznaczników medialnej tabloidyzacji, m.in. są to: zmiana proporcji pomiędzy czasem emisji informacji miękkich (soft news) i twardych (hard news) - czas, jak się uważa, jest podstawowym kwantyfikatorem ważności konkretnej informacji (newsa); dominują tematy krajowe i tematy związane $\mathrm{z}$ historiami zwykłych ludzi, sprawami społecznymi, kulturą popularną ${ }^{21}$. Podobnie wyglądają wyznaczniki świadczące o tabloidyzacji polityki. Profesor Piontek zalicza do nich: rosnącą liczbę polityków w materiałach dziennikarskich; fragmentaryzację wypowiedzi (wybór tych części wypowiedzi, które wpisują się w sposób prezentowania wydarzeń); koncentrację na liderach jako osobach, a nie przywódcach ideowych; przewage wypowiedzi polityków o innych politykach, a nie bieżących problemach czy też wydarzeniach; skracanie przez dziennikarzy dystansu wobec polityków $^{22}$, obserwowalne w wypowiedziach, relacjach i komentarzach ${ }^{23}$. Do tych elementów można by dodać zasygnalizowaną przez profesora Marka Cichockiego ${ }^{24}$, postępującą erozję społeczeństwa (erozję więzi społecznych). Ponieważ - jak podkreśla - „zanika rola mediów jako miejsca cyrkulacji opinii i poglądów. Te zastępowane są przez informacje zupełnie pozbawione znaczenia, podobne do ciekawostek, które można znaleźć na kapslach od soków [...] tracimy miejsce, gdzie można porozmawiać wspólnym językiem"25. Postępuje proces zamykania się społeczeństwa - erozji, wzrasta natomiast konieczność sporego upraszczania przekazów społecznych, ich rysowania w kategoriach, które są zrozumiałe i łatwo przyswajalne: czyli wspomniana już przeze mnie dychotomia: dobro-zło, wierzący-niewierzący, prawdziwy i nieprawdziwy obywatel.

20 Ibidem, s. 188.

21 D. Piontek, Komunikowanie..., op. cit., s. 191 i dalej.

22 W tym temacie patrz: A chciałam zostać aktorkq. Z Janinq Paradowska rozmawia Marta Stremecka, Warszawa 2011, s. 103-104.

23 D. Piontek, Komunikowanie..., op. cit., s. 202-203.

24 Prof. Marek Cichocki, filozof, redaktor naczelny „Teologii Politycznej”.

25 http://natemat.pl/34795,tabloidyzacja-mediow-tabloidyzacja-umyslow-czy-grozi-nam-erozja-demokracji (listopad 2012). 


\section{Przypadek Nergala}

Opisane powyżej zjawiska i procesy, które towarzyszą przemianom współczesnej polityki coraz bardziej zbliżają ją w stronę tabloidalnego rankingu popularności. Jednak publiczna dyskusja na temat miejsca artysty Nergala w społeczeństwie (albo poza nim) znacznie rozszerzyła znany dotąd kontekst. Jest to przykład takiego działania, które bardzo mocno - po raz kolejny w naszej historii - uwidoczniło powiązanie $s a$ crum z profanum, spraw religijnych z politycznym dyskursem. Pokazało podział społeczeństwa (jak już zaznaczyłam wyżej) na dobrych - wierzących i złych - niewierzących. Ta sytuacja jest jednak w jednym wymiarze szczególna. Rozegrała się bowiem z jednej strony na łamach prasy opiniotwórczej, z drugiej strony jednocześnie toczyła się na łamach tabloidów i portali plotkarskich, ukazując istniejący już przecież od jakiegoś czasu tabloidalny wymiar polskiej sceny politycznej.

John Street w artykule Celebrity politicians. Popular Culture and Political Representation napisał, że coraz liczniejsza jest grupa polityków. którzy sięgają po techniki mające zapewnić im zwiększenie popularności medialnej. Aby ten efekt osiagnąć, można skorzystać z trzech technik:

1) wykorzystanie gwiazd w reklamie politycznej;

2) wykorzystanie niestandardowych kanałów i formatów do promocji politycznej;

3) adaptowanie technik i wiedzy eksperckiej specjalistów od marketingu celebrities $^{26}$.

To z czym mieliśmy do czynienia jesienią 2011 roku, wydaje się doskonale wpisywać w drugi punkt Streetowskiej strategii. Polski przypadek to klasyczna chęć wykorzystania niestandardowego formatu do promocji politycznej polegający na wywołaniu spekulacji o zagrożeniu dla demokracji. A jednocześnie jest doskonałym ,produktem tabloidalnym” - dla „tabloidowych konsumentów”27, który umieszczony został gdzieś na styku tabloidalnej polityki i tabloidalnej kultury.

26 J. Street, Celebrity politicians. Popular culture and Political Representation, „The British Journal of Politics \& International Relations”, vol. 6, issue 4, Article first published online: 22 October 2004, s. 437-438, tekst dostępny na: http://onlinelibrary.wiley.com/doi/10.1111/j.1467-856X.2004.00149.x/pdf.

27 Więcej na ten temat patrz: M. Janicki, Prawdoidy z tabloidów, „Polityka”, nr 41, 10.10-16.10.2012, s. 23-26. 
Cała sprawa zaczęła się banalnie. Pan Darski został poproszony o udział w jury nowego formatu telewizyjnego - programu muzycznego „The Voice of Poland”. Jeszcze przed emisją pierwszego odcinka pojawiły się oświadczenia polityków ze sztabu Prawa i Sprawiedliwości, że obecność w programie emitowanym przez TVP osoby, która w swojej pracy artystycznej wykorzystuje przedmioty i symbolikę przywołująca satanizm, jest skandalem na miarę ogólnopolską. Tu trzeba wspomnieć, że we wrześniu 2007 roku, na (co trzeba podkreślić) zamkniętym koncercie w gdyńskim klubie „Ucho”, wokalista zespołu Behemoth Adam Darski vel Nergal podarł Biblię i nazwał ją kłamliwą księgą. Ktoś ten fragment happeningu nagrał i zamieścił w Internecie. Po upływie dwóch, czy też trzech lat na to nagranie natrafili pomorscy politycy PiS i złożyli zawiadomienie do sądu o popełnieniu przestępstwa i urażeniu uczuć religijnych. To wydarzenie bezpośrednio przyczyniło się do nagłośnienia sprawy w 2011 roku $^{28}$. Trzeba odnotować, że w sierpniu sąd uznał, iż Nergal nie popełnił przestępstwa z art. 196 kodeksu karnego (obraza uczuć religijnych), bo to, co zrobił, „było swoistą formą sztuki wpisaną w stylistykę grupy Behemoth" 29 . Nie było wobec tego żadnych prawnych dowodów i powodów, aby w jakikolwiek sposób zabraniać panu Darskiemu obecności w przestrzeni publicznej. W maju 2012 roku sprawa trafiła do Sądu Najwyższego. Sam Darski komentując to wydarzenie powiedział, że nie miał zamiaru obrazić niczyich uczuć religijnych - „Jeśli atakujemy jakieś poglądy na ulicy z transparentem czy cegłówką, to jest to złe. Scena jest miejscem, gdzie możemy się wyrażać w taki sposób, w jaki chcemy: to jest ring, to jest jak kino, jak teatr"30.

Mimo tego w sierpniu 2011 roku do protestu antynergalowego przyłączyli się dziennikarze skupieni wokół Katolickiego Stowarzyszenia Dziennikarzy, oświadczając $\mathrm{w}$ oficjalnym liście protestacyjnym, że udział Adama „Nergala” Darskiego - ,zdeklarowanego satanisty i wroga chrześcijańskich wartości - [...] stoi w sprzeczności z Misją Telewizji Polskiej jako nadawcy publicznego". Stowarzyszenie przypomniało rów-

28 http://mojawiarakatolicka.blox.pl/2011/09/Awantura-o-Nergala.html (maj 2012).

${ }^{29}$ K. Wiśniewska, Jak Nergal biskupów rozsierdzit, „Gazeta Wyborcza” 14.09.2011, http://wyborcza.pl/1,76842,10283129,Jak_Nergal_biskupow_rozsierdzil.html (maj 2012).

${ }^{30}$ Nergal obraził uczucia religijne? Sprawa do Sadu Najwyższego, http://www.wirtualnemedia.pl/artykul/nergal-obrazil-uczucia-religijne-sprawa-do-sadu-najwyzszego (maj 2012). 
nież, że zgodnie z uchwałą Zarządu TVP z 1994 r. pt. „Misja Telewizji Publicznej jako nadawcy publicznego", telewizja ma się odwoływać do wartości chrześcijańskich i narodowych ${ }^{31}$.

Kolejna fala krytyki nastąpiła (jak się można domyśleć) ze strony głównego pokrzywdzonego - czyli Kościoła katolickiego. We wrześniu biskupi podpisali żądające wyjaśnień listy do prezesa TVP Juliusza Brauna. Przykładowo biskup Wiesław Mering (diecezja wrocławska) stwierdził, że „Zatrudnienie wyznawcy satanizmu, bluźniercy, człowieka bez podstawowej kultury w telewizji publicznej bije wszelkie granice przyzwoitości: najpierw dlatego, że TV publiczna jest utrzymywana w znacznym stopniu z abonamentu - jest czymś prymitywnym drażnić tych, którzy nas utrzymują, ${ }^{32}$. „Nie zgadzamy się na publiczne promowanie satanizmu" - apelował prymas Polski abp Józef Kowalczyk ${ }^{33}$. Biskup Sławoj Leszek Głódź, metropolita gdański, pisał: „Szanowny Panie Prezesie. Pragnę zwrócić uwagę na głębokie zaburzenie stosunku zarządzanej przez Pana Spółki do misji społecznej obowiązującej telewizję publiczną. Nie może iść komercja przed dbałością o tkankę życia społecznego, ani chęć przyciągnięcia widzów przed kultywowaniem wartości budujących Naród"34. Solidarność z tymi oświadczeniami złożyła również świecka i duchowna rada społeczna przy biskupie płockim Piotrze Liberze ${ }^{35}$.

Sytuację, która jak widać w przeciągu sierpnia i września nabrała już medialnego rozpędu, postanowił wykorzystać w swojej kampanii wyborczej Jarosław Kaczyński. Podczas wizyty w Częstochowie, na Jasnej Górze, mówił: „Profanowany jest krzyż. Mamy do czynienia z propagandą małżeństw homoseksualnych, a nawet adopcji dzieci przez te małżeństwa. Mamy do czynienia z czymś, naprawdę w życiu publicznym zupełnie nowym $-\mathrm{z}$ propagandą satanizmu. Przedstawiciel tego ruchu ma być ważnym człowiekiem w TVP"36. Środowisko skupione

31 Nergal w TVP to promowanie satanizmu, „Gazeta Wyborcza” 30.08.2011, http://wyborcza.pl/1,75478,10197022,Nergal_w_TVP_To_promowanie_sataniz$\mathrm{mu}_{\overline{3}} \cdot \mathrm{html}$ (maj 2012).

$\overline{32}$ K. Wiśniewska, Jak Nergal biskupów rozsierdził, „Gazeta Wyborcza” 14.09.2011, http://wyborcza.pl/1,76842,10283129,Jak_Nergal_biskupow_rozsierdzil.html (maj 2012).

33 Ibidem.

34 Ibidem.

35 Ibidem.

36 Kaczyński straszy Nergalem i staje w obronie krzyża!, Fakt.pl, 23.09.2011, http:/www.fakt.pl/Kaczynski-straszy-Nergalem-i-staje-w-obronie-krzyza-,artykuly, 115668,1.html (maj 2011). 
wokół PiS w wokaliście zaczęło upatrywać przyczynę i jednocześnie powód kryzysu demokracji w Polsce. Podział na zwolenników i przeciwników Nergala, a co za tym idzie orędowników i piewców Prawa i Sprawiedliwości i abnegatów był tylko kwestią czasu.

W połowie września sejmowa Komisja Kultury i Środków Przekazu uznała, że sytuacja, która zaistniała w Telewizji Polskiej S.A., stworzyła poważne zagrożenie dla ładu demokratycznego w Polsce ${ }^{37}$. Jak twierdzi dokument, komisja „Z głębokim niepokojem” przyjęła zgodę zarządu TVP na udział w programie „The Voice of Poland” emitowanym w TVP2 „satanisty publicznie obrażającego chrześcijańskie wartości”. Zdaniem posłów ta sytuacja jest ,zaprzeczeniem istoty misji publicznej oraz rażącym naruszeniem prawa godzącym w fundament wspólnoty narodowej" 38 .

„Polska znalazła się w stanie wojny” - napisał w Gazecie Wyborczej Marcin Celiński - „dokładnie w stanie wojny są katolicy, podstępnie napadnięci przez Gazetę Wyborczą i PO”39. Ten element przeniósł dyskusję na zupełnie nową płaszczyznę - wiary, tradycji i historii narodowej. Jeżeli popatrzymy na całą sytuację w sposób pragmatyczny, w państwie świeckim i neutralnym światopoglądowo, incydent z Negralem powinien mieć tylko wymiar prawny, interpretacji zjawiska artystycznego wyrazu. W polskiej rzeczywistości stał się jednak podstawą do pytania o polską demokrację i wzajemnych oskarżeń, uderzających w duchową i mentalną sferę egzystencji społecznej.

Ową wojnę mentalną i światopoglądową we wrześniu na łamach portalu Fronda.pl ogłosił Tomasz Terlikowski: „Kilka miesięcy temu pisałem, że »Gazeta Wyborcza« przygotowuje swoich czytelników na wojnę z katolikami. Teraz widać już, że wojna ta się zaczęła, że znaleźliśmy się pod zmasowanym ostrzałem, a ceną przegranej bitwy będzie całkowite wypchnięcie wierzących katolików z przestrzeni publicznej”40. I dalej w grudniu mogliśmy przeczytać: „Jeśli ktoś, kto publicznie drze

37 B. Wegglarczyk, Nergal - morderca demokracji, „Gazeta Wyborcza” 15.09.2011, http://wyborcza.pl/1,76842,10293033,Nergal__morderca_demokracji.html\#ixzz1uJOTqz8D (maj 2012).

${ }^{38}$ Nergal zagraża demokracji. Posłowie o „, The Voice of Poland”, „Newsweek. Polska" 15.09.2011, www.newsweek.pl (maj 2012).

${ }^{39}$ M. Celiński, Szatan w TVP, „Gazeta Wyborcza” 20.09.2011, http://wyborcza.pl/1,75515,10318796,Szatan_w_TVP.html\#ixzzluHT0ABeo (maj 2012).

${ }^{40}$ T. Terlikowski, To ju亠̇ jest wojna, Fronda.pl, 16 września 2011, http://www.fronda.pl/news/czytaj/tytul/terlikowski:_to_juz_jest_wojna_15474 (maj 2012). 
Biblie, krzyczy do ludzi na temat Pisma Świętego »ludzie nie żryjcie tego g...« i wyśpiewuje pochwałę morderców może robić za autorytet w TVP, »Newsweeku«, i być dla katoliczek $\mathrm{z}$ »GW « »naszym towarem eksportowym « - to w istocie możemy już w Polsce wszystko. A winę za to ponoszą ludzie, którzy obecnie bronią Nergala"41.

Trafny do tej sytuacji jest komentarz Tomasza Jastruna, który ukazał się na łamach Newsweeka: „Gdy spotykam się z Adamem Darskim, więcej w nim widzę Adama niż Nergala. Ostrzegam: »Demonizacja tworzy demony. A ty nie dosyć, że sam siebie demonizujesz, to jesteś przedmiotem demonizacji «"42.

W październiku Prezes TVP Juliusz Braun w rozmowie z ks. dr. Bolesławem Karczem, prezesem Katolickiego Stowarzyszenia Dziennikarzy, przyznał, że zatrudnienie w show Nergala było błędem, jednak wykluczenie go z programu jest niemożliwe, ponieważ część odcinków została już nagrana, a ze względu na umowy z producentem i sponsorami nie można wstrzymać emisji ${ }^{43}$.

Sam zainteresowany ową sytuację komentował bardzo skromnie i w zasadzie zdawkowo. W wywiadzie dla „Zwierciadła” Darski powiedział Jastrunowi: „Stałem się częścią politycznej gry. Ok, rozumiem. Zaskakuje mnie tylko skala tego zjawiska. Ja naprawdę mam naturalnie wbudowany dystans i jestem skromnym chłopakiem, więc kiedy ktoś mówi, że jestem takim samym zagrożeniem dla demokracji jak al-Kaida albo porównują mnie do Hitlera, to... no sam nie wiem, czy się śmiać, czy płakać. Na szczęście czuję, że dym powoli opada. Tak powyborczo"44

Wywiad udzielony Maksymilianowi Rigamonti na łamach „Newsweeka”, znacznie osłabił polityczne ciosy. Nergal stwierdził bowiem: „Całe to zamieszanie to także promocja dla mnie i moich poglądów - w ich mniemaniu niebezpiecznych i złych. Dziękuję ślicznie i proszę

41 T. Terlikowski, Obrońcy Darskiego i Jedwabne, Fronda.pl, 9 grudnia 2011, http://www.fronda.pl/news/czytaj/tytul/terlikowski:_obroncy_darskiego_i_jedwabne_15379/(maj 2012).

${ }^{42}$ T. Jasturn, Bóg i szatan walczq o Polskę, „Newsweek” 27.10.2011, http://www.newsweek.pl/wydania/1316/bog-i-szatan-walcza-o-polske,83739,1,1 (maj 2012).

43 Prezes TVP: Nergal w programie „, The Voice of Poland” to bład, „Przegląd Bałtycki” 13.10.2011, http://www.dziennikbaltycki.pl/artykul/461407,prezes-tvp-nergal-w-programie-the-voice-of-poland-to-blad,id,t.html? cookie=1 (maj 2012).

44 Nergal: Porównuja mnie do Hitlera, 17 listopada 2011, http://muzyka.onet.pl/ newsy/metal/nergal-porownuja-mnie-do-hitlera,1,4909661, wiadomosc.html (maj 2012). 
o jeszcze! Ja się w tym programie nie znalazłem po to, aby udawać kaznodzieję. Telewizja jest miejscem, w którym robię wysokiej jakości rozrywkę i tyle. A polem bitwy jest dla mnie scena, ale - i to proszę zapamiętać - nie walczę z ludźmi, walczę jedynie z intelektualnym betonem" ${ }^{\text {"45 }}$. Natomiast na pytanie: Pan jest satanista, panie Adamie? Odpowiedział: „Jestem wolnym człowiekiem. Nie lubię wchodzić do szuflad, do których ludzie mnie wpychają. Żyję według własnych zasad"46.

Sprawa Darskiego nie znalazła jednak finału mimo orzeczenia sądu. 29 września 2011 roku Ryszard Nowak złożył apelację do wyroku Sądu Rejonowego w Gdyni. Rok później (październik 2012 r.) Sąd Najwyższy odpowiedział, iż „Przestępstwo obrazy uczuć religijnych popełnia nie tylko ten, kto chce go dokonać, ale także ten, kto ma świadomość, że może do niego dojść " ${ }^{47}$. O odmowę wydania uchwały wniósł obrońca Nergala mec. Jacek Potulski. Jego zdaniem, samo działanie w ramach swobody artystycznej znosi bezprawność działania oskarżonego. Obecny w SN Nergal powiedział, że „broni swojej wolności”, że poczuły się obrażone osoby, które nie były na koncercie, porównał również swój proces do „Procesu” Franza Kafki ${ }^{48}$.

Sprawa Darskiego zatoczyła jeszcze jedno koło - tym razem międzynarodowe. Parę dni po decyzji Sądu Najwyższego oficjalnie głos w tej sprawie zabrała Komisja Europejska, która w oświadczeniu - jak poinformował EUObserver.com - stwierdziła, że oskarżanie zespołu muzycznego o obrazę uczuć religijnych jest niezgodne z wartościami Unii Europejskiej i że chociaż przepisy dotyczące bluźnierstwa są wewnętrzną sprawą każdego kraju, to wszystkie kraje członkowskie UE muszą respektować pakty międzynarodowe. Komisja powołała się przy tym na Europejską Konwencję Praw Człowieka ${ }^{49}$. Sprawa wypowiedzi Komisji nie była komentowana w mediach masowych, ale informację o tym wydarzeniu można było odnaleźć na portalach plotkarskich - typu pudelek, pomponik i podobnych.

45 Polacy to waleczni głupcy, rozmowa z Adamem Darskim, Nergalem, rozm. M. Rigamonti, „Newssweek” 2011, nr 37, s. 18.

46 Ibidem, s. 19.

47 http://wiadomosci.gazeta.pl/wiadomosci/1,114871,12763018,Czy_Nergal_obrazil_uczucia_religijne_SN_Jezeli_mial.html (październik 2012).

${ }^{4-} \mathrm{http}: / /$ muzyka.interia.pl/metal/news/nergal-sad-najwyzszy-odpowiedzial-na-pytanie-prawne,1857532,47 (październik 2012).

49 http://wiadomosci.wp.pl/kat,59154,title,Komisja-Europejska-broni-Adama-Darskiego-Nergala,wid,15061110,wiadomosc.html (listopad 2012). 
Pojawiły się za to kolejne artykuły i komentarze dotyczące już nie tyle „sprawy Darskiego”, co samego Darskiego - celebryty, gwiazdy medialnej (patrząc na okładkę magazynu „Gala"50, na której Nergal przyodziany został w ogromne czarne futro). Druga odsłona problemu i ponowne jego nagłośnienie - nabrało już znacznie płytszego charakteru. Opierając się na definicji prof. Piontek - można stwierdzić, że nabrała tabloidowego charakteru, z hard news - będącego podstawą do dyskusji o wierze, katolicyzacji i laicyzacji społeczeństwa polskiego, konieczności oddzielenia państwa od Kościoła, stała się soft news - promującym się w mediach komercyjnych i na portalach popularno-plotkarskich. Sam Darski w kolejnym już wywiadzie dla „Wprost” piętnuje zaistniałą sytuację. Na pytanie Magdaleny Rigamonti; „A pan, kiedy uznał, że na walce z Kościołem zbuduje swoją karierę?", Nergal odpowiada: „Złośliwi mówią, że jestem populistą i oportunistą i że tego biednego Ryszarda Nowaka też wykorzystuję do celów propagandowych [...] Oczywiście, tej sprawie można było ukręcić łeb dużo wcześniej",51.

Kolejną pożywką dla mediów tabloidowych były zdarzenia z końca października 2012 roku. Najpierw zdjęcia Darskiego z ks. Bonieckim, komentarz Nergala umieszczony na jednym z komunikatorów społecznych: „Sprezentowałem mu [Ks. Bonieckiemu - przyp. aut.] »Spowiedź heretyka ${ }^{52}$ i uścisnąłem rękę... zaskoczył mnie prosząc o dedykację. Ks. Adam Boniecki stanął w mojej obronie w niejednej debacie publicznej, narażając się tym samym hierarchom kościelnym. Szacunek i sympatia ponad podziałami? Jestem na TAK",53.

Następnie pojawienie się wokalisty w sądzie z ,Tygodnikiem Powszechnym" pod pachą obudziło kolejną fale spekulacji i płytkich dyskusji ${ }^{54}$. Warto w tym miejscu wspomnieć o listopadowym komentarzu ks. Bo-

50 Dwutygodnik „Gala”, nr 21, 15-23.10.2012, okładka z Nergalem i wywiad Żadnych grzechów nie pamiętam.

51 Nasz Szatan, z Adamem Darskim rozmawia Magdalena Rigamonti, „Wprost”, nr 42, 21 października 2012, s. 18.

52 Spowiedź heretyka, wywiad rzeka z Adamem Nergalem Darskim - rozmawiają Piotr Weltrowski, Krzysztof Azarewicz. Premiera książki miała miejsce 17 października 2012 r.

53 http://www.fakt.pl/Nergal-i-ks-Boniecki-Ksiadz-do-Nergala-Poprosze-autograf,ar-tykuly,184003,1.html (listopad 2012).

54 http://wiadomosci.dziennik.pl/wydarzenia/galeria/408997,1,adam-nergal-darski-zzespolu-behemoth-przed-sadem-za-podarcie-biblii-na-koncercie-przyniosl-do-sadukatolickie-pismo-tygodnik-powszechny-galeria-zdjec.html (październik 2012). 
nieckiego dla gazety „Polska The Times”; na pytanie Eweliny Nowakowskiej o książkę Darskiego powiedział ${ }^{55}$ : „Do tej pory udało mi się przeczytać tylko jedną trzecią tej książki, ale już teraz mogę stwierdzić, jaka jest hierarchia wartości tego człowieka oraz co jest dla niego najważniejsze. Adam Darski to człowiek inteligentny, szalenie zaangażowany w swoją działalność artystyczną - mówił Boniecki. - I w mojej ocenie, w jego hierarchii wartości te są bardzo wysoko postawione. Siłą rzeczy, jeśli takie osoby aranżują pewne rozmowy, to w wywiadach rzekach kreują swój autoportret".

Podsumowując należy zadać trzy istotne pytania. Po pierwsze, czy przez miniony rok nie mogliśmy niejako w zwolnionym tempie obserwować, jak przebiegają procesy trywializowania przekazu medialnego. Czy obraz Darskiego nie stał się tabloidalny, a polityczno-religijno-społeczne podłoże analizowanego przeze mnie problemu nie odeszło przypadkiem w niepamięć? (tu należy mieć nadzieje, że mimo wszystko tak się nie stało i poruszona wrażliwa nuta religijności i wolności politycznej ożywiła niektóre środowiska - o czym dalej).

Po drugie, co awantura w sprawie Nergala mówi o stanie państwa? Sytuacja ta odsłoniła z jednej strony słabość systemu demokratycznego, skoro jego zagrożenia upatrywano w artyście-muzyku, jeszcze dwa-trzy lata temu bardziej rozpoznawalnym w Stanach Zjednoczonych niż w Polsce. W naszym kraju jest o nim głośno dopiero od 2009 r. od romansu z artystką Dorotą Rabczewską vel Dodą ${ }^{56}$. Z drugiej strony pokazała, że zaufanie obywateli do polityki i do polityków jest tak niskie, że aby chociaż na chwilę zwrócić uwagę społeczną, muszą chwytać się metod niestandardowych, a nawet trącących śmiesznością. Spadek i tak niewysokiego wyjściowo zaufania dobrze unaoczniają comiesięczne badania CBOS dotyczące zaufania Polaków do polityki ${ }^{57}$. Skoro do obywateli nie przemawia merytoryka polityczna, należało poszukać innej - nią właśnie okazała się celna broń, a mianowicie poszukiwanie zwolenników na płaszczyźnie tabloidalnej. Wysoka tabloidyzacja przekazu nie jest już tylko spekulacją lub zdarzeniem okazjonalnym. Stała się ona

55 „Polska The Times”, 23 listopada 2012, wywiad Eweliny Nowakowskiej z Ks. Bonieckim, jeszcze tego samego dnia materiał zniknął z internetowego portalu gazety.

56 Na plotkarskim (ale poczytnym) serwisie Pudelek.pl od 2009 roku ukazało się 405 newsów o Darskim. Szczególne nasilenie to lata 2010-2011.

57 Przykładowo patrz: Zaufanie do polityków $w$ marcu, badanie CBOS nr BS/43/2012, Warszawa 2012, autor badania Agnieszka Cybulska. 
świadomie stosowanym narzędziem; o czym świadczyć może wywiad Jacka Żakowskiego, z przywołaną wyżej Doda, na łamach „Polityki, ${ }^{\text {"5 }}$, o demokracji, polityce, życiu... Pewnie nie dziwią już słowa prof. Janusza Czapińskiego, że wszyscy gonimy Dodę ${ }^{59}$, bo to ona jest wyznacznikiem i kwintesencją „pokolenia Iksów”. Jeżeli Doda jest memowym kompleksem pokoleniowej zmiany, to dlaczego Nergal nie może być wyznacznikiem upadku polskiej demokracji? W tych rejestrach teoria Chantal Mouffe dotycząca polityczności w świecie postpolityki nie znajdzie żadnych wartości, na których można by zbudować nowy ład.

Po trzecie, zaistniała sytuacja wskazała na jeszcze jedną, znamienną cechę ewolucji współczesnego demokratycznego systemu politycznego: dyskurs polityczny w coraz większym stopniu przenosi się poza etatowy świat polityki partyjno-parlamentarnej; coraz bardziej i intensywniej prowadzony jest na płaszczyźnie kultury (także masowej), w szerokiej bazie społecznej, z wykorzystaniem poziomych i interaktywnych metod i narzędzi komunikacji. Tutaj też zdaje się on być dużo bliższy owemu pierwotnemu konfliktowi, o którym pisze Chantal Mouffe. I tak to politycy - jeszcze niedawno na zasadzie monopolu konsolidujący i artykułujący opinię publiczną - stają się poniekąd zmuszeni, aby sięgać do tej sfery publicznej dyskusji, w której ważne jest, czy jest się „,dobrym katolikiem", gdzie nie ma sensu przypominać o rozdziale Kościoła od państwa, bo tylko utrzymując dychotomię - wierny-niewierny, dobry-zły można wykrystalizować swoją pozycję w oczach społeczeństwa. Czy zatem można postawić tezę, że społeczeństwo demokratyczne niedalekiej przyszłości będzie mogło obyć się w ogóle bez owej demokratycznej nadbudowy?

Obecna sytuacja pokazała, że mimo wszelkich deklaracji politycznych, urzędowych oraz konstytucyjnej wykładni, iż Polska nie jest państwem wyznaniowym, a świeckim i neutralnym światopoglądowo; mamy do czynienia z dyskursem polityczny o podłożu stricte religijnym. Jako społeczeństwo nie byliśmy gotowi na Nergala (albo kogokolwiek innego, kogo poglądy i poczucie wolności intelektualnej i osobistej będa odmienne od tej, którą uznaje się za „państwową”). Oczywiście, nie o artystę Nergala tu chodzi, chociaż to on doskonale zogniskował spór.

58 Patrz: Zderzenie światów, rozmowa Jacka Żakowskiego z Dodą, „Polityka”, nr 18, www.polityka.pl (maj 2012).

59 Zderzenie pokoleń, z prof. Januszem Czapińskim rozmawia Jacek Żakowski, „Polityka”, nr 19, s. 20-22. 


\section{Bibliografia}

Annusewicz O., Celebrytyzacja polityczna, „Studia politologiczne” 2000, vol. 20.

Blachnicki B., Obywatele na scenie życia politycznego - ewolucja czy rewolucja, w: Współczesna przestrzeń polityczna. Ewolucja czy rewolucja, red. M. du Vall, M. Majorek, A. Walecka-Rynduch, Kraków 2011.

Dobek-Ostrowska B., Komunikowanie polityczne i publiczne, Warszawa 2007, s. 243.

Dahlgren P., The tranformation of democracy?, za: T. Olczyk, Politrozrywka i popperswazja. Reklama telewizyjna w polskich kampaniach wyborczych XXI wieku, Warszawa 2009.

Etzioni-Halevy E., Władza w demokracji: teoria elit demokratycznych, w: Przyszłość demokracji. Wybór tekstów, red. P. Śpiewak, Warszawa 2005.

Janicki M., Prawdoidy z tabloidów, „Polityka”, nr 41, 10.10-16.10.2012.

Mouffe Ch., Polityczność. Przewodnik krytyki politycznej, Warszawa 2008.

Mistewicz E., Idee nieważne, ważna władza, „Uważam Rze”, nr 4.

Mediatyzacja kampanii politycznych, red. M. Kolczyński, M. Mazur, S. Michalczyk, Katowice 2009.

Nasz Szatan, z Adamem Darskim rozmawia Magdalena Rigamonti, „Wprost”, nr 42, 21 października 2012.

Olczyk T., Politrozrywka i popperswazja. Reklama telewizyjna w polskich kampaniach wyborczych XXI wieku, Warszawa 2009.

Piontek D., Komunikowanie polityczne i kultura popularna. Tabloidyzacja informacji o polityce, Poznań 2011.

Polacy to waleczni glupcy, rozmowa z Adameme Darskim, Nergalem, rozm. M. Rigamonti, „Newssweek”, nr 37.

Rubis L., Polityka i widowisko, w: Mediatyzacja kampanii politycznych, red. M. Kolczyński, M. Maur, S. Michalczyk, Katowice 2009.

Sierakowski S., Prawica: cynizm i zmęczenie, „Gazeta Wyborcza” z 18-19.08.2007.

Zaufanie do polityków w marcu, badanie CBOS nr BS/43/2012, Warszawa 2012, autor badania Agnieszka Cybulska.

Zdański J., Demokracja w dobie społeczeństwa medialnego, w: Mediatyzacja kampanii politycznych, red. M. Kolczyński, M. Mazur, S. Michalczyk, Katowice 2009.

Zderzenie światów, rozmowa Jacka Żakowskiego z Dodą, „Polityka”, nr 18.

Zderzenie pokoleń, z prof. Januszem Czapińskim rozmawia Jacek Żakowski, „Polityka", nr 19.

Van Zoonen L., Polpular culture as political Communications, za: D. Piontek, Politycy i media. Sposoby wplywania przez polityków na zawartość mediów, w: Polska scena polityczna. Środowiska-komunikacja polityczna-strategie, red. K. Sobolewska-Myślik, A. Hess, K. Kowalczyk, Kraków 2010. 


\section{Netografia}

Jastrun T., Bóg $i$ szatan walczq o Polskę, „Newsweek” 27.10.2011, http://www.newsweek.pl/wydania/1316/bog-i-szatan-walcza-o-polske,83739,1,1 (maj 2012).

Street J., Celebity politicians. Popular culture and Political Representation, „The British Journal of Politics \& International Relations", vol. 6, issue 4, Article first published online: 22 October 2004, s. 437-438, tekst dostępny na: http://onlinelibrary.wiley.com/doi/10.1111/j.1467-856X.2004.00149.x/pdf.

Machnik B., Postpolityka. Idee nieważne - ważna władza, „Nowa Politologia” 20.05.2011, artykuł dostępny na: http://www.nowapolitologia.pl/politologia/marketing-polityczny/postpolityka-idee-niewazne-wazna-wladza (maj 2012).

http://teksty.org/bayer-full,prezydent,tekst-piosenki (maj 2012).

http://polska.newsweek.pl/-czlowiek-jest-najwazniejszy--psl-ma-piosenke-wyborcza,81252,1,1.html (maj 2012).

http://mojawiarakatolicka.blox.pl/2011/09/Awantura-o-Nergala.html (maj 2012).

Nergal w TVP to promowanie satanizmu, „Gazeta Wyborcza” 30.08.2011, http://wyborcza.pl/1,75478,10197022,Nergal_w_TVP_To_promowanie_satanizmu_html (maj 2012).

Kaczyński straszy Nergalem $i$ staje $w$ obronie krzyża!, Fakt.pl, 23.09.2011, http://www.fakt.pl/Kaczynski-straszy-Nergalem-i-staje-w-obronie-krzyza-,artykuly,115668,1.html (maj 2011).

Nergal zagraża demokracji. Postowie o „The Voice of Poland”, „Newsweek. Polska” 15.09.2011, www.newsweek.pl (maj 2012).

Nergal obraził uczucia religijne? Sprawa do Sadu Najwyższego, http://www.wirtualnemedia.pl/artykul/nergal-obrazil-uczucia-religijne-sprawa-do-sadu-najwyzszego (maj 2012).

Celiński M., Szatan w TVP, „Gazeta Wyborcza” 20.09.2011, http://wyborcza.pl/1,75515,10318796,Szatan_w_TVP.html\#ixzz1uHT0ABeo (maj 2012).

Terlikowski T., To już jest wojna, Fronda.pl, 16 września 2011, http://www.fronda.pl/news/czytaj/tytul/terlikowski:_to_juz_jest_wojna_15474 (maj 2012).

Terlikowski T., Obrońcy Darskiego i Jedwabne, Fronda.pl, 9 grudnia 2011, http://www.fronda.pl/news/czytaj/tytul/terlikowski:_obroncy_darskiego_i_jedwabne_15379/ (maj 2012).

Prezes TVP: Nergal w programie ,The Voice of Poland” to bład, „Przegląd Battycki”" 13.10.2011, http://www.dziennikbaltycki.pl/artykul/461407,prezes-tvp-nergal-w-programie-the-voice-of-poland-to-blad,id,t.html?cookie=1 (maj 2012).

Nergal: Porównuja mnie do Hitlera, 17 listopada 2011, http://muzyka.onet.pl/newsy/metal/nergal-porownuja-mnie-do-hitlera,1,4909661,wiadomosc.html (maj 2012). 
Węglarczyk B., Nergal - morderca demokracji, „Gazeta Wyborcza” 15.09.2011, http://wyborcza.pl/1,76842,10293033,Nergal__morderca_demokracji.html \#ixzz1uJOTqz8D (maj 2012).

Wiśniewska K., Jak Nergal biskupów rozsierdził, „Gazeta Wyborcza” 14.09.2011, http://wyborcza.pl/1,76842,10283129,Jak_Nergal_biskupow_rozsierdzil.html (maj 2012).

http://wiadomosci.dziennik.pl/wydarzenia/galeria/408997,1,adam-nergal-darski-z-zespolu-behemoth-przed-sadem-za-podarcie-biblii-na-koncercie-przyniosl-do-sadu-katolickie-pismo-tygodnik-powszechny-galeria-zdjec.html (październik 2012).

http://www.fakt.pl/Nergal-i-ks-Boniecki-Ksiadz-do-Nergala-Poprosze-autograf,artykuly,184003,1.html (listopad 2012).

http://wiadomosci.gazeta.pl/wiadomosci/1,114871,12763018,Czy_Nergal_obrazil_uczucia_religijne_SN_Jezeli_mial.html (październik 2012).

http://muzyka.interia.pl/metal/news/nergal-sad-najwyzszy-odpowiedzial-na-pytanie-prawne,1857532,47 (październik 2012).

http://natemat.pl/34795,tabloidyzacja-mediow-tabloidyzacja-umyslow-czy-grozi-namerozja-demokracji (listopad 2012).

\section{Politicality, politics and Mister Nergal in the context of the tabloidization of political stage in Poland}

\section{Summary}

The purpose of this paper is to analyze public discussion on the place of the artist Nergal in Polish society (or outside of this society). This discussion has significantly expanded the present context of the tabloidization of political stage and the dimension of politicality. As indicated by Chantal Mouffe, modern politicality is played out in the "moral register". The conflict between "right and left" wing is replaced by the "struggle between good and evil". Politicians have 'used' a private individual, or the artist-celebrity - Adam Darski, to create a powerful social dichotomy, dividing society into good, religious, Catholic believers who condemn the staged artistic expression of the Behemoth band and the bad, non-religious, non-Catholic non-believers who are indifferent to how religious symbols are used.

What is peculiar is the fact that this discussion took place in the opinion-forming press on the one hand and in tabloids and gossip services on the other. This undoubtedly demonstrated the tabloid-like dimension of the Polish political stage, which has been observable for some time now, although all sides were convinced they were acting as a defender of Polish democracy. 